\title{
A non-native voice
}

The EFL Gazette's editorial of August 92 discusses issues that have often been raised in $E T$. The monthly newspaper of the ELT world evidently receives a growing number of letters from non-native speakers of English who want to teach the language outside their own countries. They ask where such jobs can be found, and the editorial says: 'The short answer is they can't.'

It adds, however, that in recent years 'the status of the non-native speaker has changed radically'. From being generally considered inferior, non-native teachers 'are now seen as equal, if not superior, to their English speaking colleagues. It is universally acknowledged that they make fine teachers, teacher trainers, materials designers. They can be anything they want to be. As long as they stay at home.'

Beyond their own countries they remain a step behind the native-speaking import, lacking some 'magic ingredient' associated with a 'good' accent, a firsthand knowledge of Anglophone culture, or up-to-date EFL methodology. Local teachers might tolerate the expatriate natives among them, but 'are less keen on competition from other non-natives. What have they got, they ask, that we haven't?'

The Gazette, however, looks towards places like eastern Europe, where whole new systems of English teaching need to be set up quickly, and asks: in such a position, "who would you ask for help? The British and Americans who fail to teach their own children languages. Or the multilingual Dutch and Scandinavians?'

It is a compelling question. In our last issue, a German and two Danes wrote about the worldwide teaching of English. One currently teaches in Germany and another in Japan, while the third is an eminent retired academic who has been a professor of English across the gamut of possibilities - in Nigeria, Oslo, and Ulster.

Non-native teachers and other skilled users of English do today have a higher profile than in the past. They are part of the great majority now, and among them are hundreds of thousands whose capacity lies well beyond that odd, often patronizing level 'the advanced learner'. Theirs is a powerful new constituency in terms of education, publishing, and the media. Their voices will, I suspect, become more and more significant as the 1990s advance, and as the old and once oh-so-natural dividing line between competent native and non-native becomes ever harder to discern. Tom McArthur

The editorial policy of English Today is to provide a focus or forum for all sorts of news and opinion from around the world. The points of view of individual writers are as a consequence their own, and do not reflect the opinion of the editorial board. In addition, wherever feasible, ET generally leaves unchanged the orthography (normally British or American) and the usage of individual contributors, although the editorial style of the joumal itself is that of Cambridge University Press.

(C) Cambridge University Press 1992. No contents may be reproduced by any means without the permission of Cambridge University Press.

English Today (ISSN 0266-0784) is a quarterly. ISBN 0521438535

Publisher: Cambridge University Press, Edinburgh Building, Shaftesbury Road, Cambridge CB2 2RU. Telephone (0223) 312393

Subscriptions: the current annual subscription price for four issues for libraries and institutions is $\sum 41$ outside North America; $£ 19$ for individuals; $£ 16$ for students and the retired; airmail $£ 9$ per year extra. Apply to Jane Crossland at the above address.

Advertising Sales: write to Anita Fern at the above address.

\section{USA AND CANADA:}

Publisher: Cambridge University Press, 40 West 20th Street, New York, NY 10011-4211. Telephone (212) 9243900.

Subscriptions: the current annual subscription price in USA and Canada for libraries and institutions is $\$ 68$; $\$ 31$ for individuals; $\$ 22$ for students and the retired. Copies are air-freighted to New York to arrive with minimum delay. Apply to Lynda DiCaprio at the above address.

Advertising Sales: write to Julia Hess at the above address.

Second class postage paid at New York, NY and at additional mailing offices.

POSTMASTER: send address changes in USA and Canada to English Today, Cambridge

University Press, 110 Midland Avenue, Port Chester, New York, NY 10573-9864.

Letters to the Editor: write to Dr Tom McArthur, Editor, English Today, 22-23 Ventress Farm Court, Cherry Hinton Road, Cambridge CB1 4HD, UK.

A call for papers: In ET s files we have cuttings/clippings from a wide range of British and North American newspapers, and a scattering of material from many other sources. If readers would care to add to our files by sending in occasional (titled and dated) materials from their local newspapers, etc., this would be a great help in widening the range of usage which we can quote in From OurFiles.

Typeset by Goodfellow \& Egan. Printed in Great Britain at the University Press, Cambridge 